\title{
LEVANTAMENTO EPIDEMIOLÓGICO E VIROLÓGICO DE CASOS SUSPEITOS DE POLIOMIELITE, NO HOSPITAL ESTADUAL JESUS, NO PERÍODO DE JANEIRO DE 1967 A MARÇO DE $1968\left(^{*}\right)$
}

\author{
Hermann G. Schatzmayr **, Akira Homma *** Itamara Meilman **** e Dirce M. \\ Villas Bôas *****
}

Os autores apresentam os resultados de isolamento de poliovírus de criancas com suspeita de poliomielite paralitica no Isolamento do Hospital Estadual Jesus do Estado da Guanabara. Nas 188 amostras computadas apresentaram-se 79 positivas, destas $73,5 \%$ de poliovírus tipo I, 25,3\% do tipo II e 1,2\% do tipo III.

Os autores mostram no Gráfico 1 , um aumento da incidência da poliomielite a partir dos últimos meses no ano de 1967. Chamam a atenção para o grande nümero de casos no grupo etário de 0-3 anos (Gráfico 2); colocam ainda em questão o melhor equacionamento do problema das vacinaçóes (Tabela 1), com estudos laboratoriais de avaliação da vacina Sabin.

$O$ estudo da procedência e sexo das crianças não permitiu maiores conclusôes, sendo levantada também a relação da idade com a incidência da poliomielite (Tabela 2), bem como a necessidade de se realizar estudos para outros enterovirus, presentes na população infantil da área estudada.

\section{INTRODUÇÃO}

Considerando que as vacinações anti-pólio em paises de clima tropical não parecem corresponder aos resultados obtidos em clima temperado, isto é, a resposta imunológica não corresponderia à dos paises de clima frio, é fundamental a análise epidemiológica e virológica, dentro das nossas possibilidades de trabalho, de todos os casos suspeitos de poliomielite nesta região (1).

Ao lado disso, observaçōes anteriores têm mostrado a predominância irregular dos poliovírus tipo I e II nos casos de poliomielite estudados em laboratório no Estado da Guanabara $(2,5,6,7)$.

O levantamento dêsses casos parece-nos primordial para melhor entendimento da distribuição dos poliovirus na região e a conseqüente esquematização das medidas de contrôle da referida virose.

\section{MATERIAL E MÉTODOS}

1 - Amostras - as amostras estudadas são oriundas de casos suspeitos de poliomielite que deram entrada no Centro de Isolamento de Pólio do Hospital Estadual Jesus, do Estado da Guanabara, local para onde é encaminhada a quase totalidade dos casos suspeitos de poliomielite, atendidos pela rêde hospitalar Federal, Estadual e doentes particulares da região.

2 - Coleta - as amostras foram coletadas por meio de aplicadores de madeira ("Swab"-retal) e levadas imediatamente a tubos contendo $3,0 \mathrm{ml}$ de solução salina tamponada de Hanks, contendo hidrolisado de Lactalbumina a $0,5 \%$ e extrato de

\footnotetext{
* Trabalho realizado pelo Jepartanento de Ciências Bi ológicas da Fundaço Ensino Fspecializado do Saúde Pública, em colaboração com o Instituto Pasteur, do Instituto Estadual de Saúde Pública * Professor Adjunto, Departamento de Ciências Biológicas, F.E.N.S.P.

** Virologista, Departamento de Ciências Biológicas, F.E.N.S.P.

*** Chefe de Seção do Centro de Isolamento de Poliomielite do Hospital Estadual Jesus. **** Instituto Pasteur, I.E.S.P., Estado da Guanabara.
} 
levedura a $0,1 \%$, adicionado de antibióticos. As amostras foram conduzidas imediatamente ao laboratório em um recipiente térmico com banho de gêlo; no la. boratório foram centrifugadas a $2.200 \mathrm{rpm}$ por 20 minutos.

o sobrenadante foi coletado, adicionados antibióticos e em seguida congelado a $-20^{\circ} \mathrm{C}$.

3 - Células - foram utilizadas as células H. Ep. 2, (3), cultivadas inicialmente em meio contendo hidrolisado de lactalbumina e extrato de levedura em solução salina de Hanks, adicionado de $10 \%$ de sôro bovino. Posteriormente, estas células foram mantidas com meio Eagle com $5 \%$ de soro bovino; para inoculação dos materiais substituiu-se o meio das células pelo meio Eagle sem sôro e, quando possível, utilizou-se líquido amniótico bovino, sempre adicionando antibióticos.

4 - Inoculação - Utilizaram-se 4 tubos, inoculando-se $0,1 \mathrm{ml}$ em 2 tubos e $0,2 \mathrm{ml}$ em outros 2 tubos. As amostras positivas foram identificadas através de neutraliza.. ção do efeito citopatogênico com soros imunes preparados em coelhos; os tubos sem CPE foram considerados negativos após o $14 .^{\circ}$ dia de leitura microscópica e essas inoculações foram repetidas por 2 vêzes para serem consideradas definitivamente negativas, no sistema de isolamento utilizado.

\section{RESULTADOS}

Foram examinadas 204 amostras de "Swab"-retal, sendo 13 prejudicadas por alta contaminação bacteriana, não sendo, portanto, possivel concluir o seu exame; 3 pacientes procedentes de outros Estados também não foram computados, dois do Estado do Espírito Santo e um do Paraná, sendo isolado poliovírus do tipo I da última amostra; portanto, do número inicial, sobraram 188 amostras que foram computadas, sendo 116 amostras (56 do Estado da Guanabara e 60 do Estado do Rio de Janeiro) no ano de 1967 e 72 amostras (38 do Estado da Guanabara e 21 do Estado do Rio de Janeiro) nos meses de janeiro, fevereiro e parte de março de 1968.
Durante o período de baixa incidência foram coletadas a quase totalidade dos casos suspeitos clìnicamente de poliomielite. Após o mês de novembro, devido ao maior volume de internamentos no Hospital, foram coletados aproximadamente $42 \%$ dos casos suspeitos.

A distribuição mensal das amostras recebidas e dos poliovírus isolados encontra-se no Gráfico 1.

A análise dêste gráfico indica com clareza um aumento da incidência de casos suspeitos de poliomielite a partir de dezembro de 1967, mostrando a curva o ponto mais elevado em janeiro de 1968 . Os registros de casos de notificações clínicas do Hospital Estadual Jesus mostram um aumento da incidência já a partir de outubro do ano de 1967. Por motivos alheios à nossa vontade, no mês de novembro não foi possível regular coleta de material, o que nāo nos permitiu acompanhar no laboratório, claramente, o início dêste aumento de incidência. De qualquer forma nos parece claro, pelos dados obtidos nos registros do Hospital Estadual Jesus que, a partir do início de 1966, a incidência de casos suspeitos de poliomielite paralítica chegou a niveis bastante baixos, estando ausente em maio de 1967, aumentando abruptamente a partir do mês de outubro.

o sistema utilizado para as coletas de material, em que um "Swab-retal era colhido algumas vêzes não mais nos primeiros dias da doença ,o uso de uma linhagem de células apenas, bem como a impossibilidade de examinar os materiais recebidos imediatamente após a coleta, devem ser os fatôres responsáveis pelo nú mero de materiais negativos, ou seja, materiais dos quais não foi possivel isolar qualquer agente citopatogênico para as células, em relação ao número de amostras recebidas para exame.

No Gráfico 2 analisamos, discriminadamente, as amostras de poliovírus, isoladas, em função da idade dos pacientes.

$A$ incidência da poliomielite na faixa de idade menor do que 3 anos, ou seja o típico aspecto da doença como paralisia infantil, como se observa em países em desenyolvimento, vem confirmar os resultados obtidos na mesma região em anos anteriores $(2,6,7)$. 


\section{DISTRIBUICĀo MENSAL dAS AMOSTRAS RECE -}

\section{BIDAS E DOS POLIOVIRUS ISOLADOS NO PE-}

\section{RIODO ESTUDADO}

- NÚMERo DE AMOSTRAS RECEBIDAS

- número oe isolamentos de. poloviaus DAS AMOSTRAS RECEBIDAS

GRÁFICO I

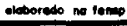

No período estudado verificou-se a predominância do tipo I, com a percentagem de $\mathbf{7 3 , 5} \%$ dos vírus isolados em comparação a $25,3 \%$ do tipo II e $1,2 \%$ do tipo III, com um total de 79 amostras isoladas.

Em relação a doses de vacina recebidas pelas crianças incluídas neste estudo, os resultados são apresentados na Tabela 1. Verificamos que do total de crianças examinadas $88,3 \%$ não haviam recebido qualquer dose de vacina oral tipo Sabin.

Quanto aos demais, verificamos que, em relação aos poliovírus tipo II isolados, apenas 1 criança havia recebido uma única dose de vacina em um total de 20 amostras. Em contraposição, nas crianças das quais foram isoladas poliovírus tipo $I$, encontram-se 5 crianças que receberam doses de vacina. Em relação ao poliovírus tipo III, nada é posstvel concluir em virtude de ter-se isolado apenas 1 amostra.

Podemos verificar, na Tabela 2, uma distribuição semelhante em relação à idade, entre os Estados da Guanabara e do Rio de Janeiro.

Quanto à residência das crianças inclui- 
AMOSTRAS RECEBIDAS, POLIOVIRUS (TIPOS $1,2,3$ )

SEGUNDO A IDADE, DURANTE O PERÍODO ESTUDA-

- do ( Jan.67 À mar.68)

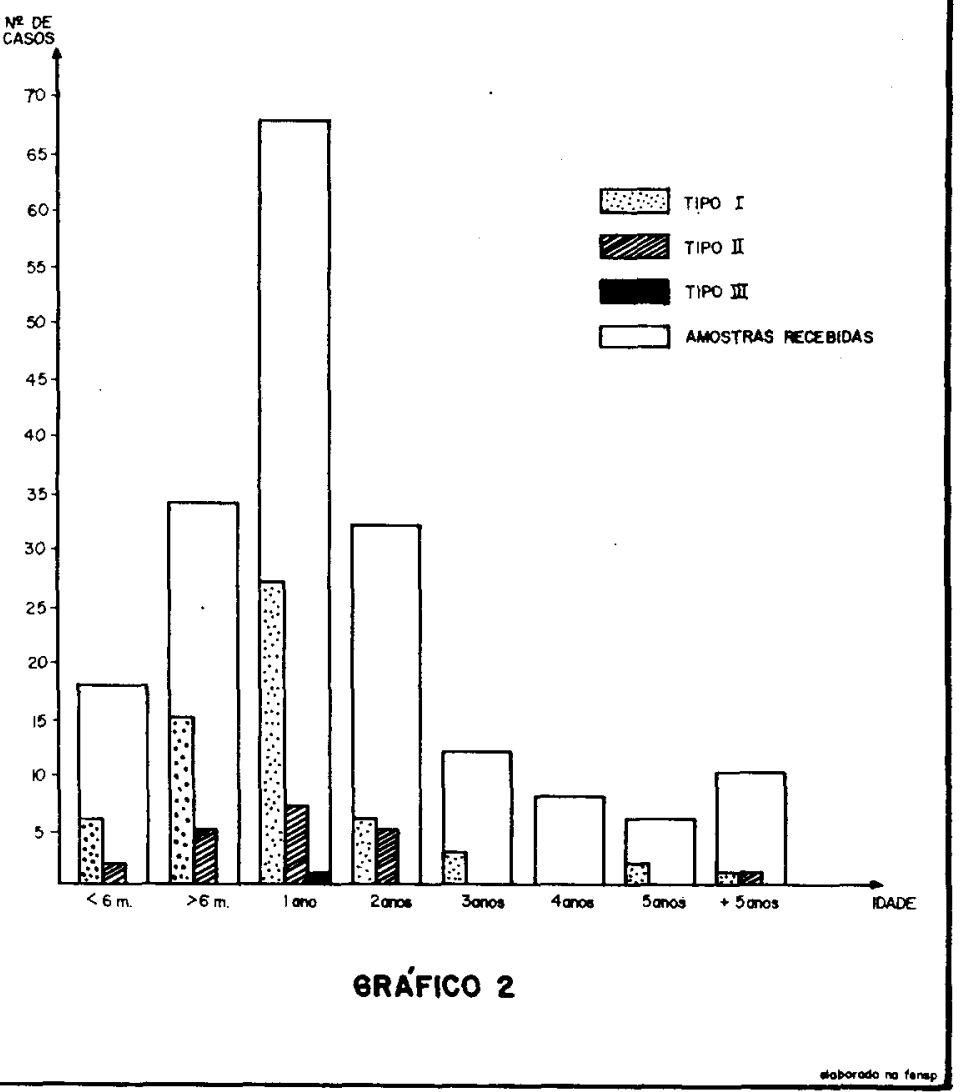

las neste estudo, verificou-se uma incilência, no Estado da Guanabara, especialnente nas zonas de baixo desenvolvimeno econômico, e em especial na zona da seopoldina. No Estado do Rio, verificou-. se predominância de algumas localidades :omo Caxias, Nova Iguaçu, Itaperuna e 3arra Mansa.

Em relação ao sexo, verificou-se uma li- geira predominância do sexo masculino, o que não nos parece, porém, ter maior significado epidemiológico.

Os dados epidemiológicos que foram possíveis de obter têm naturalmente as limitações naturais dadas as condições de trabalho e as condições socio-econômicas dos responsáveis. Em relação às crianças procedentes do Estado da Guanabara e que 
receberam vacina Sabin, os dados fornecidos pelos responsáveis foram confirmados pelos Postos de Vacinação.

\section{DISCUSSÃO}

O isolamento de um vírus das fezes de um individuo não constitui por si só o diagnóstico da infecção por poliomielite neste indivíduo. Tal fato é principalmente importante quando encontramos uma comunidade ainda sofrendo uma imunização natural, ou seja, comunidade que não tenha sido inteiramente vacinada (5). A análise sorológica mostrando um aumento significativo de títulos de anticorpos cons- titui elemento importante da técnica de diagnóstico. Além disso, evidentemente, constituem os dados clínicos - especialmente quando é possível acompanhar o desenvolvimento das sequelas - dado da mais alta importância.

Em nosso caso, foi possivel lançar mão do isolamento do vírus, juntamente com a cuidadosa observação clínica. Não nos foi possivel realizar a análise dos anticorpos em virtude da dificuldade de se estabelecer uma rotina de coleta.

Considerando a Tabela 1 , verificamos uma maior percentagem de culturas positivas nas crianças sem nenhuma dose de vacina que em aquelas que receberam vacina Sabin.

Na mesma Tabela 1, observa-se que das crianças que receberam vacina das quais foi possivel isolar Poliovírus tipo II, apenas uma em vinte havia recebido uma única dose de vacina, enquanto que, entre as crianças das quais se isolou poliovírus do tipo I, cinco crianças de um total de 58 haviam recebido uma, duas ou mesmo três doses da vacina.

filste dado, embora iragmentário pelo pequeno número de amostras estudadas, parece indicar uma resposta menos eficiente em relação à amostra do tipo I da vacina.

Tal fato necessita evidentemente de urgente e definitiva confirmação, pois teria extraordinária importância para o estabelecimento das condições adequadas para a imunização da população infantil no nosso meio.

A distribuiçăo mensal dos casos de poliomielite paralítica pode ser, em países de clima temperado, bem relacicnada à época do ano. De fato, nas épocas mais quentes do ano, há nesses países, um aumento dos enterovírus na população e conseqüentemente da infecção por poliovírus, desde que evidentemente as medidas de imunização não tenham modificado o padrão acima descrito. Em países como o nosso, porém, o estudo da distribuição dos casos mostra uma tendência a um irregular predomínio dos periodos epidêmicos. Assim, por exemplo, tivemos em 1965 a incidência máxima de poliovirus no mês de agôsto, enquanto que no período aqui descrito tivemos uma predominância no mês de janeiro. O real significado, porém, dessa irregular distribuição exige um apurado levantamento dos dadcs disponiveis, quando todos os fatôres em jôgo poderiam ser, então, analisados.

Poliovírus tipo I mostrou-se predominante, o que nos parece de importância pois estudos anteriores, na mesma região, mostraram (6) que o tipo II predominou nos casos de paralisia. Surge pois, o tipo I como predominante, após um periodo de baixa incidência de poliomielite paralítica, como foi o de janeiro de 1966 até setembro de 1967.

Mesmo assim o tipo II ainda se apresentou com $25,3 \%$ do total de isolados de poliovirus no periodo estudado.

Esta alternância entre um e outro tipo confirma inteiramente os resultados obtidos na África (4). Naqueles estudos, o tipo I parece ser o responsável pelas epidemias, surgindo o tipo II principalmente nos períodos inter-epidêmicos. Seria esta alternância de tipos uma característica de regiōes tropicais? Teria esta alternância algum significade no processo de imunização artificial dessas regiões?

Comparando-se o grupo etário de menos de 1 ano, procedente do Estado do Rio e do Estado da Guanabara, verifica-se maior incidência de poliomielite naquelas crianças originárias do Estado do Rio.

Esses dados poderiam sugerir um diferente padrão de infecção inicial nos dois Estados. Por outro lado deve-se ter em conta as condições de saneamento das diversas regióes de onde procederam os pacientes estudados, dado êste que não pode ser levantado com absoluta segurança. Consideramos, no entanto, que ficou mais uma vez evidenciado serem a região geo-econômica do Estado da Guanabara e re- 
TIPOS DE POLIOVIRUS ISOLADOS E VACINA.

CĀO SABIN NOS

PACIENTES

\begin{tabular}{|c|c|c|c|c|c|}
\hline \multirow{2}{*}{$\begin{array}{l}\text { VACINA } \\
\text { SABIN }\end{array}$} & \multicolumn{4}{|c|}{ POLIOVIRUS } & \multirow[b]{2}{*}{ TOTAL } \\
\hline & $T$ & II & III & NEG. & \\
\hline \begin{tabular}{l|l}
0 & 1 \\
w & 1 \\
0 & 2 \\
0 & 3 \\
\end{tabular} & $\begin{array}{l}2 \\
1 \\
2 \\
\end{array}$ & $\begin{array}{l}1 \\
- \\
\end{array}$ & $\overline{-}$ & $\begin{array}{l}8 \\
1 \\
7\end{array}$ & $\begin{array}{r}11 \\
2 \\
9 \\
\end{array}$ \\
\hline NĀO VA & 53 & 19 & 1 & 93 & 166 \\
\hline TOTAL & 58 & 20 & 1 & 109 & 188 \\
\hline
\end{tabular}

PROCEDÊNCIA DAS AMOSTRAS ESTUDADAS, SEGUNDO A IDADE NO PERIODO ESTUDADO

\begin{tabular}{c|c|c|c}
\hline \multirow{2}{*}{ IDADE } & \multicolumn{2}{|c|}{ PROCEDENCIA } & \multirow{2}{*}{ TOTAL } \\
\cline { 2 - 3 } & GB & RJ & \\
\hline$<6 \mathrm{~m}$. & 8 & 10 & 18 \\
$>6 \mathrm{~m}$. & 13 & 21 & 34 \\
1 ano & 36 & 32 & 68 \\
2 anos & 18 & 14 & 32 \\
3 anos & 5 & 7 & 12 \\
4 anos & 5 & 3 & 8 \\
5 anos & 5 & 1 & 6 \\
+5 anos & 4 & 6 & 10 \\
\hline TOTAL & 94 & 94 & 188 \\
\hline
\end{tabular}

TABELA 2 
giōes limitrofes do Estado do Rio uma única comunidade epidemiológica em relação à poliomielite.

Tendo em vista, ainda, o idêntico número de crianças internadas de um ou outro Estado e considerando que, evidentemente, - Hospital Estadual Jesus atende maior número de pacientes do Estado da Guanabara do que do Estado do Rio de Janeiro, julgamos que houve desta vez uma maior taxa de incidência no Estado do Rio de Janeiro do que no Estado da Guana.. bara. Isso, aliás, viria confirmar as medidas de vacinação como eficazes no contrôle da poliomielite na região.

A taxa de mortalidade em tôrno de $5 \%$ representa valor mais baixo do que aquela encontrada em anos anteriores, o que mostra uma relativa menor virulência das amostras isoladas no periodo estudado.

Cumpre-nos salientar aqui, em primeiro lugar, os bons resultados obtidos nos anos de 1966 e grande parte de 1967 com a relativa baixa de incidência de poliomielite bem como enfatizar a necessidade urgente da avaliação de vacina oral tipo Sabin em nosso meio, tendo em vista a presença de crianças vacinadas entre os pacientes de poliomielite paralitica. Êste fato tem sido observado em regiões tropicais, quando da avaliaçāo da vacina oral nesta região (4).

Parece-nos indiscutível que a vacina necessita uma avaliação cuidadosa, tendo em vista os múltiplos fatôres que podem concorrer em nosso meio para uma deficiente formação de anticorpos. Necessário se torna, por exemplo, a determinação da incidência de outros enterovírus não-pólio na área estudada.

\section{AGRADECIMENTOS}

Os autores agradecem à biologista $\mathrm{Ma}$ ria Lucilia 'Pessoa Loureiro, pelo seu trabalho no cuidado e manutenção das culturas de células usadas neste estudo.

\section{$S U M M A R Y$}

The authors present results obtained by the inoculation in tissue culture of material from rectal swabs of suspected paralitic Polio cases, at the Hospital Jesus, at Rio de Janeiro. Among 188 swabs that have been examinated, Poliovirus could be demonstrated in 79 cases $(73,5 \%$ were positive for type $I$, $25,3 \%$ for type II and 1,2\% for type III).

An increase of paralitic Polio cases in the last months of 1967 could be demonstrated. Most of the children belong to the age group between zero to 36 months old and were not vaccinated; however, some of the children got one, two or three doses of trivalent vaccine. It is emphasized that serological studies should be done in this area in order to better understanding the multipie factors involved in the response to the vaccination, including the determination of the incidence of non-polio agents in the population.

\section{BIBLIOGRAFIA}

1 - Crônica da OMS - 21: n. ${ }^{\circ}$, pág. 105, 1967.

2 - HUBINBER, M.G.V., VILLAAS BôAS, D.M. \& SCHATZMAYR, H.G. Estudos sôbre casos de poliomielite aguda no Estado da Guanabara. O Hospital, 71: 107-110, 1967.

3 - MOORE, A.E.L. SABOCHEWSKY \& H.W. TOOLAND - Culture characteristics of four permanent lines of human cancer cells. Cancer Res., 15: 598-602, 1955 .

4 - Relatório da Comissão de Poliomielite da Nigéria - Poliomyelitis vac- cination in Ibadan, Nigéria, during 1964, with Oral Vaccine (Sabin strains) Bull. Wld. Hlth. Org., 34: 865-86, 1966.
5 - SCHATZMAYR, H.G. \& COSTA, L.T. - Isolamento do vírus da poliomielite a partir de material de garganta em uma comunidade rural. Bol. Inst. Puer. Univ. Brasil, 22: ..... 135-138, 1965.

6 - SCHATZMAYR, H.G. \& COSTA, L.T. - Estudos sôbre Poliomielite no Estado da Guanabara: Preodominância do Tipo II em caso de Paralisia. Bol. Inst. Puer. e Ped. M.G., 23: 38-42, 1966.

7 - SCHATZMAYR, H.G. \& VILLAS BOAS, D.M. - Presença do Típo I em casos de Poliomielite Aguda no Estado da Guanabara. Rev. Inst. Med. Trop., 8: 246-248, 1966. 


\section{REGULAMENTO DO PREMIO GERHARD DOMAGK}

Art. $10^{\circ}-O$ prêmio Gerhard Domagk é oferecido anualmente a partir de 1963, pela A CHIMICA "BAYER" S.A. em comemoração do centenário da fundação da FARBENFABRIKEN BAYER AG., de Leverkusen, Alemanha, ao autor ou autôres do melhor trabalho sôbre temas de medicina tropical (Doenças Infectuosas e Parasitárias, de Nutrição, Fisiologia e Higiene Tropicais), uma vez que o mesmo satisfaça às exigências dêste Regulamento.

Art. $2 .^{\circ}$ - Concorrerão ao referido prêmio todos os trabalhos publicados na REVISTA DA SOCIEDADE BRASILEIRA DE MEDICINA TROPICAL durante $O$ ano anterior.

Art. $30^{\circ}$ - O prêmio constará de uma importância em dinheiro, estipulada anualmente, e de uma medalha com o respectivo diploma assinado pelo Presidente e Secretário-Geral da Sociedade. No caso de trabalho em colaboração, o prêmio em dinheiro será conferido à equipe, porém cada um dos co-autores receberá uma medalha e um diploma, que mencionará ser o prêmio pertencente à equipe.
Art. $4^{\circ}$ - Serão membros da Conissão Julgadora o Presidente da SocieJade Brasileira de Medicina Tropical, que a presidirá, e os integrantes do Conselho Consultivo da REVISTA DA SOCIEDADE BRASILEIRA DE MEDICINA TROPICAL.

Art. 5. - Cada membro da Comissão Julgadora indicará os 5 melhores trabalhos publicados durante o ano, sendo premiado aquêle que obtiver maior número de votos. Caberá ao Presidente da Sociedade Brasileira de Medicina Tropical a decisão final em caso de empate.

Art. $6 .^{\circ}$ - A Comissão Julgadora deverá emitir seu parecer até a data do início do Congresso anual da Sociedade Brasileira de Medicina Tropical, quando o prêmio será entregue em sessão solene.

Art. $7 .^{\circ}$ - Não caberá qualquer recurso ao parecer da Comissão Julgadora.

Art. 8..$^{\circ}$ - O Presidente da Sociedade Brasileira de Medicina Tropical será árbitro supremo para decidir as dúvidas surgidas na interpretação dêste Regulamento ou resolver qualquer dificuldade em sua execução. 